\title{
Horizontal acquisition of Symbiodiniaceae in the Anemonia viridis (Cnidaria, Anthozoa) species complex
}

\author{
Barbara Porro ${ }^{1}$ (D) Thamilla Zamoum ${ }^{1}$ (D) Cédric Mallien ${ }^{1}$ (D) Benjamin C. C. Hume ${ }^{2}$ (C) \\ Christian R. Voolstra ${ }^{3}$ (C) Eric Röttinger ${ }^{1}\left(\right.$ C $\quad$ Paola Furla $^{1}$ (C) $\quad$ Didier Forcioli $^{1}$ (C)
}

${ }^{1} \mathrm{CNRS}$, INSERM, Institute for Research on Cancer and Aging (IRCAN), Université Côte d'Azur, Nice, France

${ }^{2}$ Red Sea Research Center, Division of Biological and Environmental Science and Engineering, King Abdullah University of Science and Technology (KAUST), Thuwal, Saudi Arabia

${ }^{3}$ Department of Biology, University of Konstanz, Konstanz, Germany

Correspondence

Didier Forcioli, CNRS, INSERM, Institute for Research on Cancer and Aging (IRCAN). Université Côte d'Azur, 28 avenue de Valombrose, 06107 Nice, France.

Email: forcioli@univ-cotedazur.fr

\begin{abstract}
All metazoans are in fact holobionts, resulting from the association of several organisms, and organismal adaptation is then due to the composite response of this association to the environment. Deciphering the mechanisms of symbiont acquisition in a holobiont is therefore essential to understanding the extent of its adaptive capacities. In cnidarians, some species acquire their photosynthetic symbionts directly from their parents (vertical transmission) but may also acquire symbionts from the environment (horizontal acquisition) at the adult stage. The Mediterranean snakelocks sea anemone, Anemonia viridis (Forskål, 1775), passes down symbionts from one generation to the next by vertical transmission, but the capacity for such horizontal acquisition is still unexplored. To unravel the flexibility of the association between the different host lineages identified in A. viridis and its Symbiodiniaceae, we genotyped both the animal hosts and their symbiont communities in members of host clones in five different locations in the North Western Mediterranean Sea. The composition of within-host-symbiont populations was more dependent on the geographical origin of the hosts than their membership to a given lineage or even to a given clone. Additionally, similarities in host-symbiont communities were greater among genets (i.e. among different clones) than among ramets (i.e. among members of the same given clonal genotype). Taken together, our results demonstrate that A. viridis may form associations with a range of symbiotic dinoflagellates and suggest a capacity for horizontal acquisition. A mixed-mode transmission strategy in $A$. viridis, as we posit here, may help explain the large phenotypic plasticity that characterizes this anemone.

KEYWORDS

clonality, cryptic species, ITS2, microsatellite, RAD-Seq, symbiosis
\end{abstract}

1

\section{INTRODUCTION}

From their earliest development stages, all metazoans live in close association with different microorganisms (symbionts) forming

Furla and Forcioli authors contributed equally to this work. a so-called holobiont (Margulis \& Fester, 1991). The evolution of these holobionts is influenced by the transmission mode of symbionts. Two modes of symbiont acquisition have been described: from the parents or from the environment, called vertical transmission and horizontal acquisition, respectively. Vertical transmission is traditionally more associated with mutualism, whereas 
horizontal acquisition corresponds more to parasitism (Moran \& Wernegreen, 2000). Vertical transmission indeed ensures the maintenance of beneficial associations at the embryonic stage (ZilberRosenberg \& Rosenberg, 2008), but with less flexibility in the host-symbiont association. A strong correlation between the host and symbionts phylogenies can therefore be expected (for a review on the topic, see Baumann, 2005). However, this binary vision of a clearly split transmission mode between mutualism and parasitism is not so obvious and many examples of mutualistic symbiosis maintained by horizontal acquisition have been observed and described (Henry et al., 2013; Kaufman et al., 1998; Nelsen \& Gargas, 2008; Rowan \& Knowlton, 1995). In such case, the horizontal acquisition, which could be hazardous because of the uncertainty in partner occurrence, is nevertheless an efficient way to obtain new or locally better adapted symbionts.

Host-symbiont acquisition is not necessarily exclusive by means of vertical or horizontal mechanisms: a situation named by Ebert (2013) as the mixed-mode transmission of symbionts. This mixedmode has already been observed in cases where host-symbiont phylogenies were not totally coupled due to occasional horizontal acquisition in holobionts alternatively classified as vertical transmitters (Stewart et al., 2008). The horizontal acquisition and the mixed-mode transmission imply some flexibility in the symbiotic association, an important point for the response to environmental variations. Indeed, if the whole holobiont is the unit of selection in a strict vertical transmission, in a mixed-mode transmission, the selective pressure could act on either hosts or symbionts as well as the holobiont level (Theis et al., 2016).

In marine Cnidaria (including hydrozoans, corals, gorgonians and sea anemones), the animal host can be associated with eukaryotic mutualistic photosynthetic symbionts (see for review Clavijo et al., 2018). These symbionts play key roles in the physiology and ecology of their hosts. Among Anthozoa, the main photosynthetic symbionts are dinoflagellates belonging to the Symbiodiniaceae family (LaJeunesse et al., 2018). Located intracellularly, these symbionts translocate most of the organic compounds they produce by photosynthesis to their host cells (Davy et al., 2012). The cnidarian-dinoflagellate symbiosis is highly diverse with the possible occurrence of multiple dinoflagellate genotypes within a given host. This diversity can be partially explained by diverse ecological factors which can lead to the presence of different dinoflagellate genotypes (see Parkinson \& Baums, 2014 for review). In addition, bacterial symbionts are involved in the good working of the cnidarian-dinoflagellate holobiont (e.g. for nitrogen cycle) and contribute to the holobiont diversity (Rohwer et al., 2002; Suggett et al., 2017). The dinoflagellate symbionts can be acquired by the cnidarian hosts via vertical transmission or horizontal acquisition (at larval or adult stages). Why vertical or horizontal symbiont acquisition modes are associated with a given cnidarian species is still not understood, but in scleractinian corals, only $25 \%$ of spawning species (i.e. those that emit their gametes directly into the ocean) have symbionts in their eggs (i.e. vertical transmission) and belong to only a few specific genera (Montipora, Acropora, Pocillopora, and Porites; Baird et al., 2009).
In contrast, temperate symbiotic sea anemones have mainly vertical 'closed acquisition systems' (Muller-Parker \& Davy, 2005). Although horizontal acquisition in adult cnidarians has been poorly studied in the field (except after postbleaching episodes and mainly for scleractinian corals (Boulotte et al., 2016; Silverstein et al., 2015)), Byler et al. (2013) demonstrated that some species, such as Stylophora pistillata, display mixed-mode transmission. The flexibility that horizontal transmission may offer to the host is particularly important considering the functional diversity of symbionts at genus or species level (Brading et al., 2011; Reynolds et al., 2008; Roberty et al., 2016; Suggett et al., 2008; Tchernov et al., 2004), and may also apply to associated bacteria (Neave et al., 2017). Even within Symbiodiniaceae species, functional genetic differentiation has been measured between two symbiont populations (Howells et al., 2012, 2020).

Using ITS2 variability, we previously investigated the genetic diversity of the symbionts hosted by Anemonia viridis, a species of symbiotic sea anemone widely distributed in Europe, from the Mediterranean Sea to the North Sea and the west coast of Ireland, in which different cryptic species (independent lineages) have been recently identified (Porro et al., 2019). In A. viridis, a unique Symbiodiniaceae clade, 'Temperate A' (LaJeunesse et al., 2018; or A' sensu Savage et al., 2002; and Visram et al., 2006), has been identified, showing a clear genetic diversity within the clade (CasadoAmezúa et al., 2014; Porro et al., 2019). This symbiont diversity was observed with respect to the geographical origin and the host lineage (Porro et al., 2019). Specifically, in this latter study, we revealed the occurrence of different assemblages of Temperate $A$ Symbiodiniaceae in at least two lineages of $A$. viridis (English Channel and Mediterranean Sea). However, as the two lineages were found in two far geographically distinct areas, it was unclear whether the symbiotic assemblage was a result of response to the environment versus a result of genetic drift in a closed system.

Anemonia viridis can reproduce both sexually, emitting gametes in the water column, and asexually, by longitudinal fission of the gastrovascular column (from the foot to the mouth, Shick, 1991). Whatever the reproduction mode, this sea anemone is thought to inherit its symbionts by vertical transmission either by (i) maternal transmission through oocytes (Schäfer, 1984; Utrilla et al., 2019) with a mean of 300 symbionts per oocytes (personal observations) or (ii) by partitioning of the symbiont population of the 'mother' between the two 'daughter' sea anemones. The vertical transmission guarantees the continuity of this important association, as the A. viridis holobiont has the potential to be completely autotrophic (Davy et al., 1996; Muller-Parker \& Davy, 2005). Even if symbiont diversity has been studied in A. viridis (Casado-Amezúa et al., 2014; Porro et al., 2019; Savage et al., 2002; Suggett et al., 2012; Visram et al., 2006), no study of the dynamics of symbiont populations at the adult stage has been conducted so far, although it would fill an important gap in the understanding of the plastic and adaptive capacities of this species. Indeed, many studies have highlighted its strong capacity for resistance to extreme and disturbed environments (Richier et al., 2005; Suggett et al., 2012; Ventura et al., 2016). In this 
context, the occasional occurrence of horizontal symbiont acquisition on top of the vertical transmission may provide a mechanism for adaptation, adding to the intergenerational stability of the association the capacity to acquire locally better adapted symbiont genotype (Parkinson \& Baums, 2014).

To determine whether a closed vertical mode of symbiont transmission occurs in Anemonia viridis or if concurrent and complementary horizontal symbiont acquisition within a mixed-mode transmission is also possible in this species, we investigated the strength of the link between host genetic diversity and symbiont assemblage. A more extensive sampling of the North Western Mediterranean Sea than in Porro et al. (2019) was used. We first delimitated reproductively isolated lineages within the $A$. viridis species complex (using RAD sequencing markers) and then compared their symbiotic contents (based on NGS acquired nuclear ITS2 and microsatellite diversity) to establish the host-symbiont genetic specificity. We also used the pervasive asexual reproduction occurring within these $A$. viridis lineages to estimate the similarity of the symbiont communities within and among different sea anemone clonal genotypes (as identified with RAD sequencing markers) sampled in distinct geographical locations. We hypothesized that, in strictly closed vertical transmission, ramets (i.e. representatives of the same clonal genotype) should be more similar in their symbiont content than two sea anemones from different genets (different clonal genotypes), irrespective of their geographical location. In contrast, the occurrence of horizontal symbiont acquisition would be revealed by a strong geographical effect independent of the lineage and/or genotype of the host.

\section{MATERIALS AND METHODS}

\subsection{Mediterranean Sea anemones}

We sampled 237 individuals of Anemonia viridis (Forskål, 1775) var smaragdina (characterized by pink tips and a green fluorescence, Mallien et al., 2017; Wiedenmann et al., 1999) from five locations in the Mediterranean eastern basin: Banyuls [Ban, 50 sea anemones sampled], Barcarès [Bar, 44], Sète [Tha, 48], Marseille [Mar, 49] and Scandola [Sca, 46] (see Figure 1 for GPS coordinates). For each sea anemone, a dozen tentacles were cut, fixed in $70 \%$ ethanol and preserved at $-80^{\circ} \mathrm{C}$ until DNA extraction. Total DNA was extracted

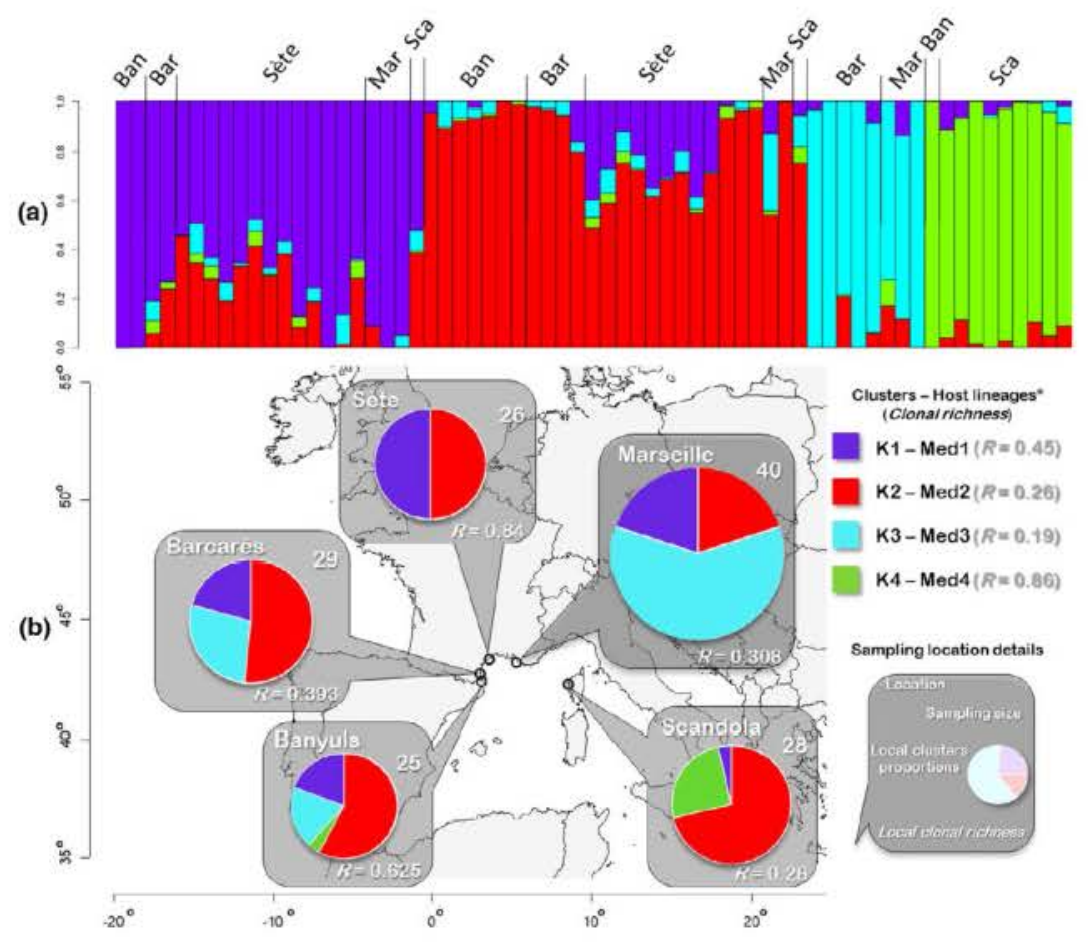

FIGURE 1 sNMF genetic clusters of Anemonia viridis and their geographic distribution in the Mediterranean Sea. (a) Bar plot representation of the sNMF analysis of the animal host (N65 data set). The genetic diversity could originate from 4 ancestral genetic clusters (named K1 to K4, respectively, in purple, red, blue and green). The bar plot represents the contribution of each of these clusters to the genetic constitution of each individual in this data set. The sampling location of each individual is mentioned above the barplot. (b) Proportion of each cluster in each sampling location (N148 data set; Table S1), along with local sample size and clonal richness R.

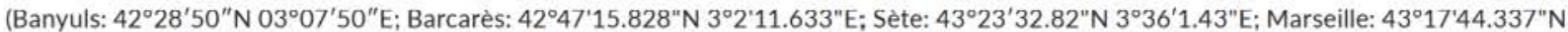
$5^{\circ} 20^{\prime} 34.348^{\prime \prime} \mathrm{E}$; Scandola: $42^{\circ} 21^{\prime} 29.571^{\prime \prime} \mathrm{N} 8^{\circ} 33^{\prime} 19.166^{\prime \prime} \mathrm{E}$ ). *Host genetic lineages correspond to genetic lineages either identified in Porro et al. (2019) (Med1 and Med2) and in the present study (Med3 and Med4), see discussion section 
as in Mallien et al. (2017) following a modified 'salting out' protocol (Miller et al., 1988).

\section{$2.2 \quad$ Host genotyping}

\subsubsection{RAD sequencing}

The ad hoc libraries were prepared following Porro et al. (2019). Sequencing was performed on an Illumina HiSeq 2000 (100-bp single read format) at the Montpellier-GenomiX platform (MGX, Montpellier, France). Raw sequence reads were demultiplexed, filtered and clustered with iPyRAD v0.3041 (Eaton, 2014) with a clustering threshold set to $90 \%$.

\subsubsection{Host data sets}

From the iPyRAD outputs, we derived a base data set by filtering on missing data: the individuals with a low proportion of shared loci were identified using the R package RADami v1.1-2 (Hipp, 2014) and removed using VCFTools v0.1.15 (Danecek et al., 2011); the loci were then filtered to only keep loci present in at least $95 \%$ of individuals (197 individuals and 25,603 SNPs) (Figure 2).

We then filtered the base data set to keep only biallelic loci with a minimum allele frequency (maf) of $1 \%$. This new data set was called N197 data set with 197 individuals and 5,299 SNPs. This data set was used to detect clonality. By selecting only the 148 individuals for which the symbionts could be genotyped (see below), we defined the N148 data set. This data set was used for host/symbiont differentiation comparison.

After clonality detection, we were able to filter the individuals from the base data set by keeping only one ramet per genet, and we only kept the biallelic loci with a maf of $1 \%$. This constituted the N65 data set with 65 individuals and 6,498 SNPs that were used for host genetic clustering and lineage identification.

The N65 data set was further filtered to keep 14 individuals only (one individual per location and genetic cluster), and for the SNPS without missing data, with a maf of $10 \%$ and a linkage disequilibrium pruning threshold (LD) of 0.2 (package SNPRelate v1.11.2; Zheng, 2012) which constituted the BFD data set of 1,197 SNPs. This data set was used for the test of species hypotheses by BFD* (see below).

\subsubsection{Detection of clonality}

Even if no anemones did share the same multilocus genotypes, we repeatedly detected similar genotypes in the sampling. These genotypes were likely a consequence of asexual reproduction events and have been grouped into multilocus lineages called genets (see Harper, 1977) in this paper (the representatives of each genet being referred to as ramets). To formally delineate these genets and associate individual samples to them, we computed between individual pairwise distances for all individuals in the $N 197$ data set (Figure 2) with the R package RClone v1.0.2 (Bailleul et al., 2016). The observed

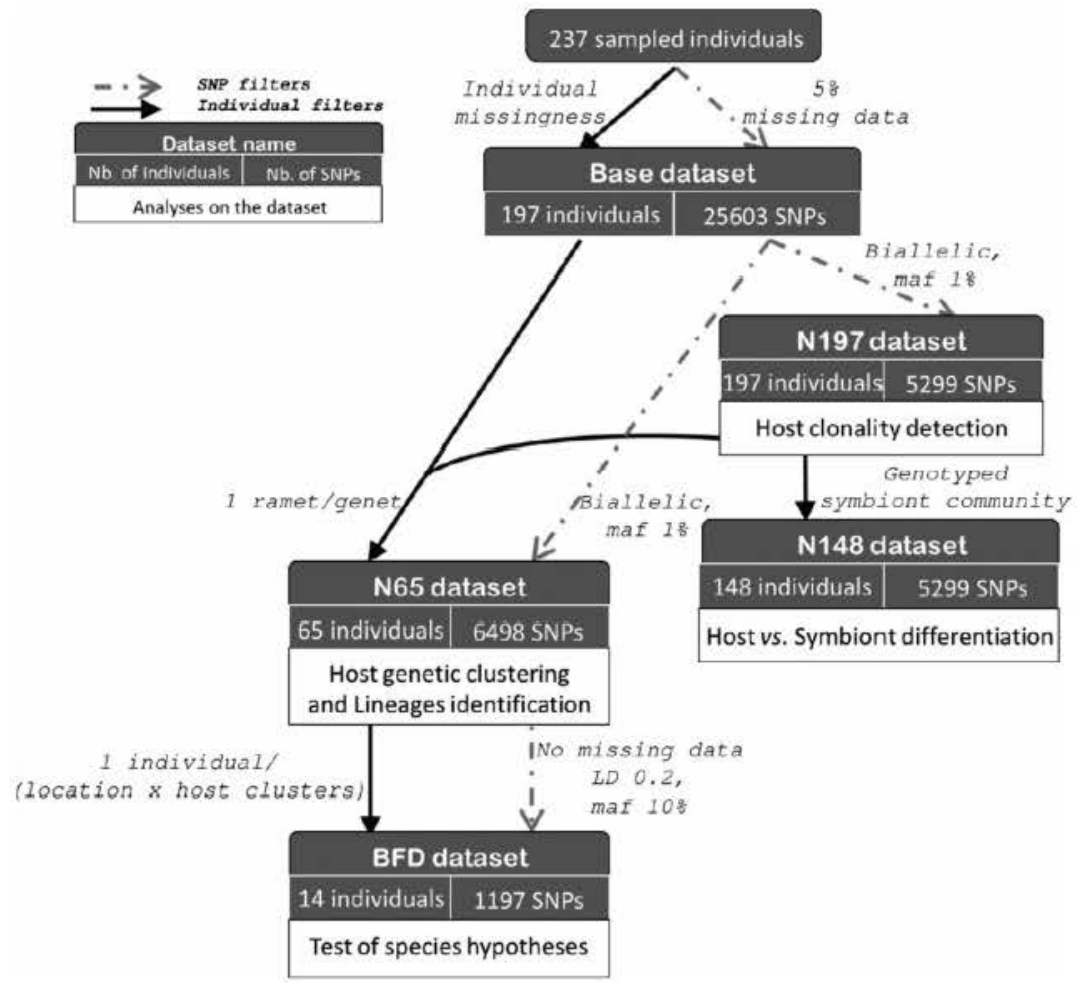

FIGURE 2 Host data sets. Description (number of individuals and SNP markers) of the different data sets used for each analysis. BFD is for Bayes factor delimitation and refers to the BFD* analysis to test species hypotheses 
distributions of pairwise genetic distances thus obtained were compared with simulated distributions of the expected genetic distances under the assumption of purely sexual reproduction (with or without selfing) computed with RClone (using the functions genet_dist and genet_dist_sim) (Bailleul et al., 2016). This allowed us to identify a gap in distance distribution and define a threshold distance value separating distances within genets from distances among genets. We could thus associate individuals to genets using the function mlg.filter (with the 'farthest_neighbor' algorithm) from the R package POPPR v2.5.0 (Kamvar et al., 2014). We then calculated the clonal richness $(R)$ considering the number of genets as the number of different genotypes over the total number of sampled sea anemones (globally, per location and per host genetic cluster).

\subsubsection{Structure of host genetic diversity}

To identify putative species within A. viridis individuals from the Western Mediterranean basin, we used the N65 data set (Figure 2) and we computed a species tree using SVDquartets (Chifman \& Kubatko, 2014) implemented in PAUP* v4.0A165 (Swofford, 1998, 2001) with an exhaustive quartet sampling and performed a SNMF quantitative hierarchical genetic clustering with the LEA (v2.2.0) R package (Frichot \& François, 2015), based on individual ancestry coefficients. The optimal number of ancestral clusters, from which the individuals in the data set could be traced back, was determined using the entropy criterion. The results were visualized using a STRUCTURE-like representation showing, for each individual, the relative contribution of each ancestral cluster to its multilocus genotype. The ramets not kept in the N65 data set were attributed by extension to the main cluster of their genet.

To test whether the SNMF clusters and SVD clades were independent species, we compared the likelihood of the species hypothesis they constitute, to the likelihood of a primary species hypothesis based on the geographical locations of the individuals using Bayes factor delimitation with genomic data (BFD*; Leaché et al., 2014). In order to manage computing times, these analyses were performed using the BFD data set (Figure 2). The BFD* analyses were performed in BEAST2 (Bouckaert et al., 2014) with 48 path sampler sets of 100,000 MCMC repetitions, to sample in 800,000 MCMC iterations of SNAPP (Bryant et al., 2012). The number of SNAPP iterations was chosen to ensure proper convergence of the species tree inference. To ensure the convergence of the computations while maintaining amenable computing times, the BFD* analyses were repeated on two partitions of the 1,197 SNPs of the BFD data set. The first analysis was run on the 598 first SNPs and the second one the other 599 SNPs of the data set.

Wright's F-statistics among and within populations were computed using the R packages StAMPP v1.5.1 (Pembleton et al., 2013) and hierfstat v0.04-22 (Goudet \& Jombart, 2015).

\section{$2.3 \quad$ Symbiont genotyping}

\subsubsection{Amplicon sequencing}

The symbiont populations were genotyped using the nuclear ribosomal DNA internal transcribed spacer 2 (ITS2). We used the primers from Stat et al. (2009): the forward itsD (5'-GTGAATTGCAGAACTCCGTG-3') and the reverse its2rev2 (5'-CCTCCGCTTACTTATATGCTT-3').

The symbiont populations were also genotyped using four microsatellites: three designed from an Expressed Sequence Tag library of A. viridis holobionts (Sabourault et al., 2009) and one from the study of Catanéo et al. (2009) (see also Abdoullaye et al., 2010) about the Temperate A symbionts from the Mediterranean gorgonian Eunicella singularis (with the NCBI Accession no FJ917549.1; Table 1). These markers are particularly useful to genotype populations instead of species (Coffroth \& Santos, 2005) as they are more informative of recent evolutionary events (Cornuet et al., 2010).

PCR amplifications of the symbiont markers were performed by Access Array (FLUIDIGM) PCR, and next-generation sequencing of the amplicons was obtained by MiSeq Illumina Technology ( $2 \times 250$ bp paired-end) at the Brain and Spine Institute (ICM, Paris, France).

\subsubsection{Genotyping methods}

Because a given sea anemone can host 3 to 20 million symbiont cells per milligram of protein (values from field and laboratory experiments; Ventura et al., 2016), the sequences obtained from each

TAB LE 1 Detail of the symbiont microsatellite markers sequenced by NGS

\begin{tabular}{|c|c|c|c|c|}
\hline Loci & Symbiodiniaceae ex & Motif & Primers (forward reverse) & References \\
\hline CAES-67 & Eunicella singularis & GT & $\begin{array}{l}\text { GTTTCGGGTCTCGGGATAGG } \\
\text { TTAGCCCCAAAAACATAAACC }\end{array}$ & $\begin{array}{l}\text { Catanéo et al. (2009) } \\
\text { (FJ917549.1) }\end{array}$ \\
\hline 64,238 & Anemonia viridis & $C A$ & $\begin{array}{l}\text { AGGGGTCTAGTTTCCCTGAC } \\
\text { GGACCGGATTTCCTCTTGC }\end{array}$ & Present study \\
\hline 71.379 & & CT & $\begin{array}{l}\text { CAGCAGTTAGTCAATTTIAAACGGC } \\
\text { TCATGGTCGGTACACTGGG }\end{array}$ & \\
\hline 72,276 & & AG & $\begin{array}{l}\text { GGGAGTTATCAAGCTGTTGGC } \\
\text { TGTTTACATGCATAAACATCAGGAC }\end{array}$ & \\
\hline
\end{tabular}


anemone were in fact obtained from a pooled sample of symbionts. Their genotyping was therefore not straightforward and required additional analysis steps.

In this context, we performed an analysis of the symbiont diversity within the $A$. viridis using ITS2 and microsatellite sequence variants. The analysis of ITS2 sequence variant assemblages is an effective method for comparing Symbiodiniaceae populations despite the marker's multicopy nature, which complicates data interpretation (see Hume et al., 2019). The ITS2 sequences were processed and identified using the SymPortal pipeline (Hume, 2019; Hume et al., 2019) based on a minimum entropy decomposition algorithm, as in Porro et al. (2019).

For the microsatellite markers, the forward and reverse reads were assembled, then trimmed and tagged by microsatellite locus using OBITools scripts (Boyer et al., 2016). To filter background noise and to identify reads with actual microsatellite repeats, we used the MicNeSs python script (Suez et al., 2016) with a tolerance of one substitution in the microsatellite motif. Because MicNeSs was designed for diploid organisms, and because we did not want to bias the genetic diversity by forcing a maximum of two microsatellite alleles per within-host-symbiont population, we chose to consider for each individual, instead of the genotype, the raw observed distribution of the reads containing a given microsatellite locus. We kept for further analysis only the sea anemones with amplification for at least three out of the 4 symbiont microsatellite markers used. Therefore, as we did not attempt to ascertain any of the microsatellite alleles present in the read collections, this raw observed distribution of the reads is more a fingerprint of the symbiont community composition than a proper collection of individual genotypes. Nevertheless, it can still be used to measure the level of differentiation in symbiont content among different sea anemones.

The symbiont populations were not successfully amplified from all the sampled individuals, and only 148 sea anemones could be genotyped for both host and symbiont microsatellite markers. These individuals composed the N148 data set (Table S1).

\subsubsection{Symbiont differentiation}

We compared the different compositions of symbiont populations using over the N148 data set, for the ITS2, the presence/absence of sequence variants among the hosts, and for the microsatellite markers, the observed relative frequency distributions of the reads. For these reasons, the differentiation between hosts in terms of symbiont community composition was expressed both as a Jaccard's distance (for ITS2 sequence variant assemblage considering the presence and absence of the variants) and a Manhattan's distance (for the distributions of microsatellite markers). The distances among hosts/symbiont community compositions were visualized with neighbour-joining trees with R package APE V5.3 (Paradis et al., 2004) with 1,000 bootstraps. We measured the correlation between symbiont population distance and host genetic distance by Mantel's tests. We also tested by PERMANOVA with the R package vegan v2.5-5 (Oksanen et al., 2016) the differences in symbiont community composition between sea anemones depending on (i) the host genetic clusters, or (ii) the sampling location. When these factors had significant effects on the distribution of the genetic diversity of the symbionts, we then computed pairwise PERMANOVAs between each level of the given factor with an FDR correction to avoid false positives. The Manhattan's distances were also used to compare the differentiation within multilacation genets. Following the approach of Baums et al. (2014) in a coral species, we took advantage of asexual reproduction in $\mathrm{A}$. viridis to test for the tightness of the closed vertical symbiont transmission in A. viridis, by comparing the symbiont diversity among ramets. If symbiont diversity is only the result of mother to offspring transfer, we expected that ramets from the same genet should have a similar symbiont community composition, and hence, the distances should be shorter compared with genetically distant hosts. The differences were statistically tested with a Kruskal-Wallis test implemented in R (R Core Team, 2018).

\section{RESULTS}

\subsection{Clonality in A. viridis var. smaragdina populations}

We detected clonality in the data set with a gap in the distribution of pairwise genetic distances among A. viridis individuals (Figure S1), and hence identified 65 genets over the 197 sea anemones sequenced, with 37 genets considered as unique (one ramet) and 28 genets (here called clonal genets) with at least two representatives (i.e. at least two ramets produced from asexual reproduction events, see Table S1). These 28 clonal genets could be found in different distant sampling locations (Table S1). We hence estimated a global clonal richness of 0.33 .

\subsection{Host genetic structure}

To identify independent genetic pools, we performed a sNMF genetic clustering. Based on minimum cross-entropy value (Figure S2), we determined $K=4$ as the optimal number of ancestral genetic clusters among the 65 genets (N65 data set). Among these four different genetic clusters, we detected admixture, more specifically two of them seemed to be more admixed (K1 and K2; Figure 1a): more than a third of the sea anemones in $\mathrm{K} 2$ where not purely descended from this cluster, and had at least $15 \%$ of their loci from K1 and, reciprocally, more than half of the sea anemones in $\mathrm{K} 1$ admixed with the K2 cluster (Figure 1a and Table S1). All these clusters were found in at least two different sampling locations (Figure 1a,b) with K2 being the most common cluster among the Mediterranean sampled populations. The admixture $\mathrm{K} 1 / \mathrm{K} 2$ was correlated with the lowest $F_{S T}$ value of 0.119 compared with the other pairwise differentiations (Table S2). The K4 cluster appeared as the most differentiated 
genetic cluster in the Mediterranean Sea with $F_{S T}$ values to other clusters ranging from 0.242 to 0.350 .

We also used SVDquartets to produce a coalescent taxonomic partitioning from the N65 data set (Figure S3). The SVDquartets analyses showed three main clades (clades 1, 3 and 4) and an unresolved group (clade 2). These clades are partially congruent with the clusters identified by the SNMF analysis: the clades 3 and 4 corresponded to the clusters K 3 and K4 respectively, and clade 1 corresponded to a part of the cluster K1 (Table S1).

To know which one of the partitions given by sNMF clustering (hypothesis 2 in Table 2) or SVDquartet clades (hypothesis 3 in Table 2) was the most likely secondary species hypothesis (SSH), we compared them to a null hypothesis (a primary species hypothesis, hypothesis 1) based on geographical origin, using BFD*. In addition to these species hypotheses, we considered another one bringing $\mathrm{K} 1$ and K2 together (hypothesis 4) because of the admixture between K1 and K2 (Figure 1a). In addition, using two different sets of host SNPs (see Material and Method section), the best SSH, using Bayes Factor comparisons, was the sNMF cluster partition (Table 2). We hence identified four different host genetic lineages in $A$. viridis Mediterranean populations.

\subsection{Symbiont differentiation}

The two types of genetic markers (ITS2 and microsatellites) used to genotype the symbiont populations from $148 \mathrm{~A}$. viridis individuals (N148 data set) revealed an overall similar picture of the symbiotic composition, with no clear partitioning of the data set based on either the obtained 122 ITS2 variants (Figure 3a) or the microsatellite markers (Figure 3b). Independently of the host genetic cluster, we further tested the correlation between host genetic distances and the differences in symbiont content. The analysis did not show global correlation either with the ITS2 assemblages (Mantel's $r=-.06$ and a $p$-value of .839 ; Figure 4a) or with the microsatellite markers (with a Mantel's $r=0.06$ and a $p$-value of .086 ; Figure 4b).
However, we detected with both types of markers a global effect of the sampling location on the symbiont composition with PERMANOVA analyses (Table 3, Tables \$3 and \$4) with similar symbiont content among host clusters at the same location (Table S4). Nevertheless, with microsatellite markers, a weak effect of the host genetic cluster was revealed (Table 3 ) mainly due to a differentiation between $\mathrm{K} 2$ and $\mathrm{K} 4$ occurring at Scandola (Table S4).

Symbiont community composition was more similar among sea anemones from the same location (intra- and interlineages Manhattan's average distances of $D=2.186$ and 2.502, respectively; Figure $5 a$ ), than within the same host lineage at different locations (intralineage interlocation, $D=2.951$ ) and finally nonrelated individuals (interlineage interlocation, $D=3.063$ ). At a finer genetic scale, we used the clonal host genets found in different locations to evaluate the differentiation of the symbiont community composition within a genet. Six of the identified genets were distributed in at least two locations with at least two ramets within a location (Table S5). If vertical transmission was the only mode of transmission of symbionts, we expected that the weakest differentiation would be observed within a genet independently of the geographical origin. However, the differences in the symbiont community composition among individuals from the same location were significantly lower (intra- and intergenets: $D=1.331,2.782$ resp.) than the differences among individuals from different locations (intra- and intergenets: $D=3.223$, 3.027 resp.; Figure $5 \mathrm{~b}$ ). Hence, the genets from the same location had similar symbiont populations.

\section{DISCUSSION}

In this study, we questioned whether the symbiont diversity observed in A. viridis adult individuals was the result of closed vertical transmission only or whether secondary horizontal acquisition and/or local selection could also occur and modify the symbiont population in respect to the environment. We showed that sea anemones belonging to the same host lineage, but sampled from different locations, harbour different symbiont communities, revealing

TABLE 2 Test of Anemonia viridis species hypotheses by BFD*. The four species hypotheses tested were (1) a geographic partitioning (the primary species hypothesis), (2) the sNMF clustering, (3) the SVDquartets partitioning and (4) an intermediate SVDquartets partitioning considering the $\mathrm{K} 1$ and $\mathrm{K} 2$ admixture. ( $\mathrm{MLE}=$ maximum-likelihood estimator, $\mathrm{BF}=$ Bayes factor). In bold, the secondary species hypothesis retained with the lowest MLE and the degree of significance when compared with the other species hypotheses

\begin{tabular}{|c|c|c|c|c|c|c|c|c|c|}
\hline & & \multicolumn{4}{|c|}{ First BFD* run (598 SNPs) } & \multicolumn{4}{|c|}{ Second BFD* run (599 SNPs) } \\
\hline & & \multirow[b]{2}{*}{ MLE } & \multicolumn{3}{|l|}{$2 \ln B F$} & \multirow[b]{2}{*}{ MLE } & \multicolumn{3}{|l|}{$2 \ln B F$} \\
\hline \multicolumn{2}{|c|}{ Species hypotheses } & & 1 versus & 2 versus & 3 versus & & 1 versus & 2 versus & $\begin{array}{l}3 \\
\text { versus }\end{array}$ \\
\hline 1 & Ban/Bar/Mar/Sca/Tha & -8844.82 & & & & -9010.55 & & & \\
\hline 2 & $\mathrm{~K} 1 / \mathrm{K} 2 / \mathrm{K} 3 / \mathrm{K} 4$ & -8478.39 & -732.85 & & & -8694.89 & -631.32 & & \\
\hline 3 & $\begin{array}{r}\text { Clade } 1 / \text { Clade } 2 / \\
\text { Clade3/Clade } 4\end{array}$ & -8506.24 & -677.16 & 55.69 & & -8713.98 & -593.15 & 38.17 & \\
\hline 4 & $\begin{array}{c}\text { (Clade1 + Clade2)/ } \\
\text { Clade3/Clade4 }\end{array}$ & -8584.71 & -520.22 & 212.63 & 156.94 & -8793.75 & -433.60 & 197.72 & 159.54 \\
\hline
\end{tabular}




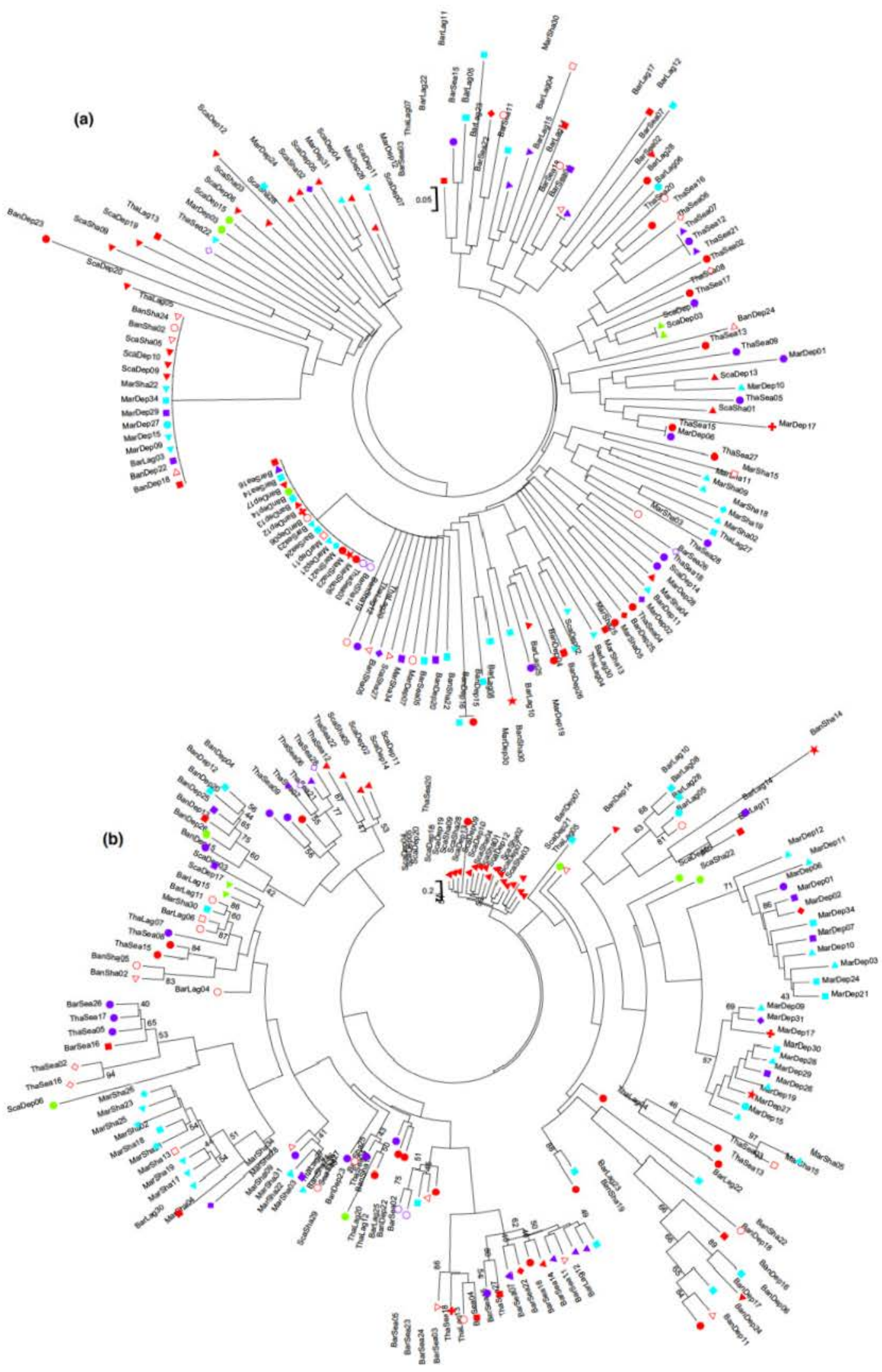


FIGURE 3 Differentiation of Anemonia viridis individuals based on algal symbiont composition (N148 data set): (a) NJ tree based on Jaccard's distances of ITS2 assemblages among the sea anemones; (b) NJ tree based on Manhattan's distances of microsatellite distributions among sea anemones. The bootstraps higher than 40 were displayed on the nodes. Colours correspond to the host genetic cluster from the Figure 1 (K1: purple, K2: red, K3: blue and K4: green); the symbols correspond to the host genets: the ramets of the same genet shared the same coloured symbol, and full circles correspond to the unique genets

FIGURE 4 Scatterplot and

Mantel's tests of pairwise host genetic distances against pairwise symbiont distances among A. viridis (N148 data set): considering, (a) the symbiont ITS2 sequences assemblage (Jaccard's distance-with a Mantel's $r=-0.06$ and $p$-value $=.839$ ); (b) the symbiont microsatellite distributions (Manhattan's distance-with a Mantel's $r=.06$ and $p$-value $=.086$ ). The dashed line indicates the threshold host distance between intragenet and intergenet distances (see Figure S1)
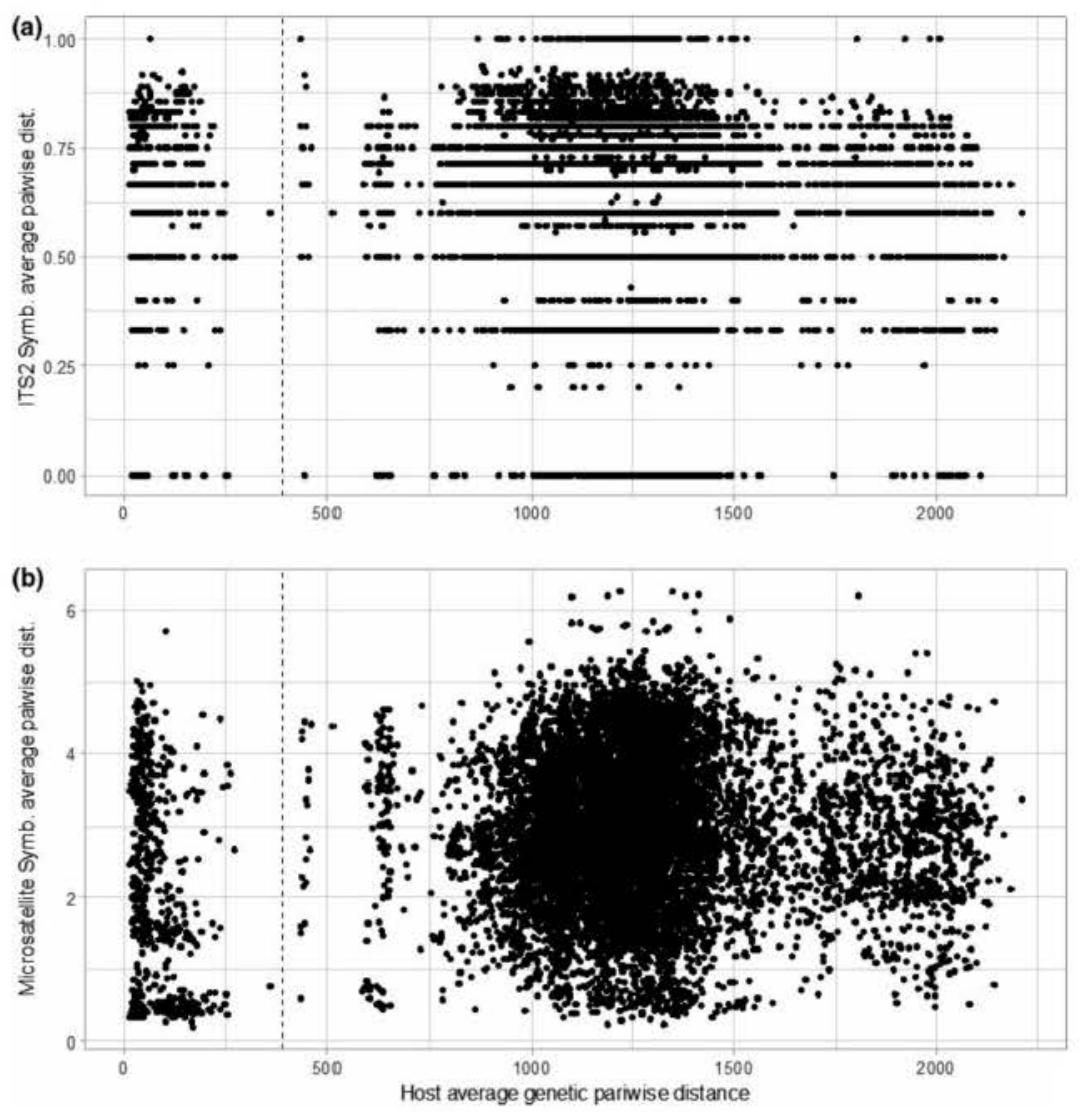

TABLE 3 PERMANOVA tests of differentiation of symbiont community compositions based on ITS2 sequences (upper part) or microsatellite distributions (lower part)

\begin{tabular}{|lllllllll}
\hline Markers & Factors & Df & $\begin{array}{l}\text { Sums of } \\
\text { squares }\end{array}$ & Mean Sqs & F.Model & $R^{2}$ & $\operatorname{Pr}(>\mathrm{F})$ \\
\hline ITS2 & Location & 4 & 2.4868 & 0.6217 & 2.92662 & 0.08028 & $1.00 \mathrm{E}-05$ \\
& Lineage & 3 & 0.6705 & 0.2235 & 1.05212 & 0.02165 & 0.3437 \\
& LocationxLineage & 7 & 1.2646 & 0.18066 & 0.85043 & 0.04083 & 0.857 \\
& Residuals & 125 & 26.5536 & 0.21243 & & 0.85725 & \\
Microsatellite & Total & 139 & 30.9755 & & & 1 & $1.00 \mathrm{E}-05$ \\
& Location & 4 & 196.64 & 49.16 & 15.152 & 0.2829 & 0.00221 \\
& Lineage & 3 & 25.66 & 8.552 & 2.636 & 0.03691 & 0.00566 \\
& LocationxLineage & 7 & 41.29 & 5.898 & 1.818 & 0.0594 & \\
& Residuals & 133 & 431.5 & 3.244 & & 0.62079 & 1 \\
\hline
\end{tabular}

Note: PERMANOVAs were realized over 99,999 permutations. The bold values indicate factors with statistically significant effect on the symbiont differentiation. 
a mixed-mode symbiont transmission. However, how different are A. viridis host lineages?

\subsection{Multiple $A$. viridis lineages in the Mediterranean Sea}

As we previously identified cryptic species in A. viridis, it was critical to first identify to which host lineage the sampled individuals belonged. After taking clonality into account, we could group the sampled individuals into 4 genetic clusters, recognized by BFD* as four differentiated lineages. As a subset of samples used in this study had already been analysed in Porro et al. (2019), we could recognize that the $\mathrm{K} 1$ and $\mathrm{K} 2$ lineages from this study corresponded, respectively, to the Med1 and Med2 lineages from Porro et al. (2019). Moreover, having increased the Mediterranean sampling density, we were now able to redefine the distribution of Med1 and Med2, which are no longer single-location lineages, and identify two new lineages, named Med3 and Med4, that corresponded to the clusters K3 and K4, respectively (Figure 1 and Table 2).

At all locations, lineages were found in sympatry with different degrees of admixture among them. These admixture signals probably explained the incongruence between quantitative genetic clustering (sNMF) and coalescent analysis (SVDquartet), with, for

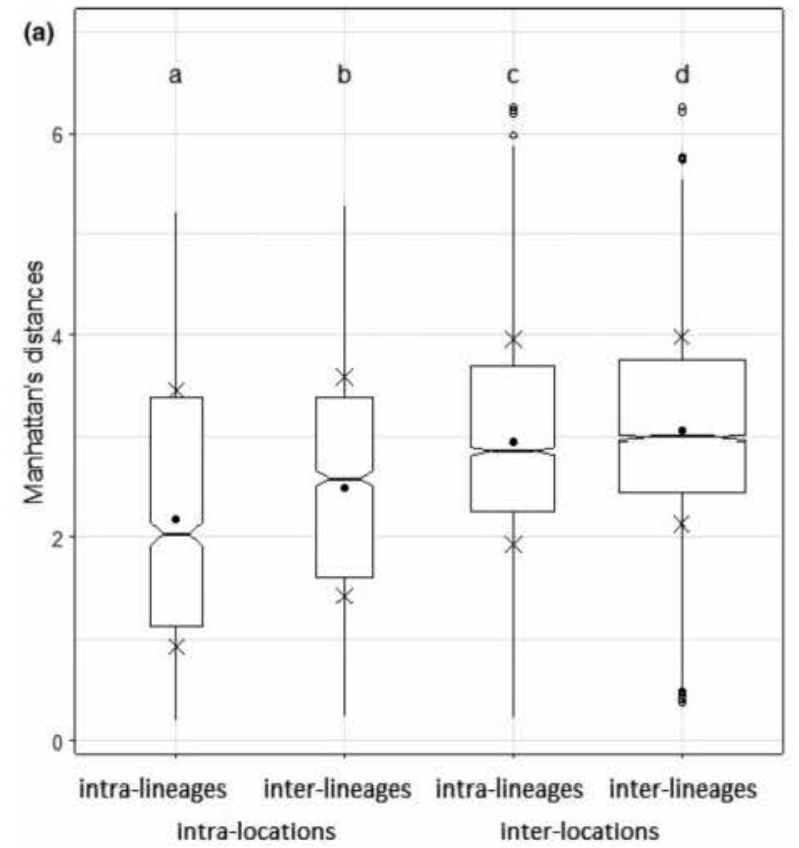

example, seven admixed individuals of the cluster $\mathrm{K} 1$ belonging to the clade 2 (Table S1). As previously found, Banyuls was the most genetically diverse location (with the presence of the four lineages), supporting our supposition of the presence of a strong contact zone between genetic pools in this Mediterranean zone (Porro et al., 2019). In addition, we now describe an ubiquitous presence of the Med2 (K2) lineage at all sites, suggesting a strong ability for this lineage to occupy different habitats and maybe great dispersal capacities as well. In all lineages and sites, we detected an important clonal richness, which confirmed that $A$. viridis can deploy genets with a great number of ramets (Mallien et al., 2017; Porro et al., 2019; Sauer, 1986; Sauer et al., 1986; Wiedenmann et al., 2000), even if, within this sampling, the Med4 (K4) lineage exhibited a much lower clonality. It is interesting to note that the Med2 (K2) lineage showed varying levels of clonality from one site to the other ( $R$ varied from 0.05 in Scandola to 0.9 in Sète), in a similar way to what had been observed in another sea anemone, Metridium senile, with different clonality rates in different locations along the N W Atlantic coast (from New York to Nova Scotia) (Hoffmann, 1986). More surprisingly, the ramets of the Med1 (K1), Med2 (K2) or Med3 (K3) genets were not always located at the same site and some genets were comprised of individuals present in distant sites (Tables 4 and S1), suggesting again a potentially high capacity of migration/dispersion in this species, as already

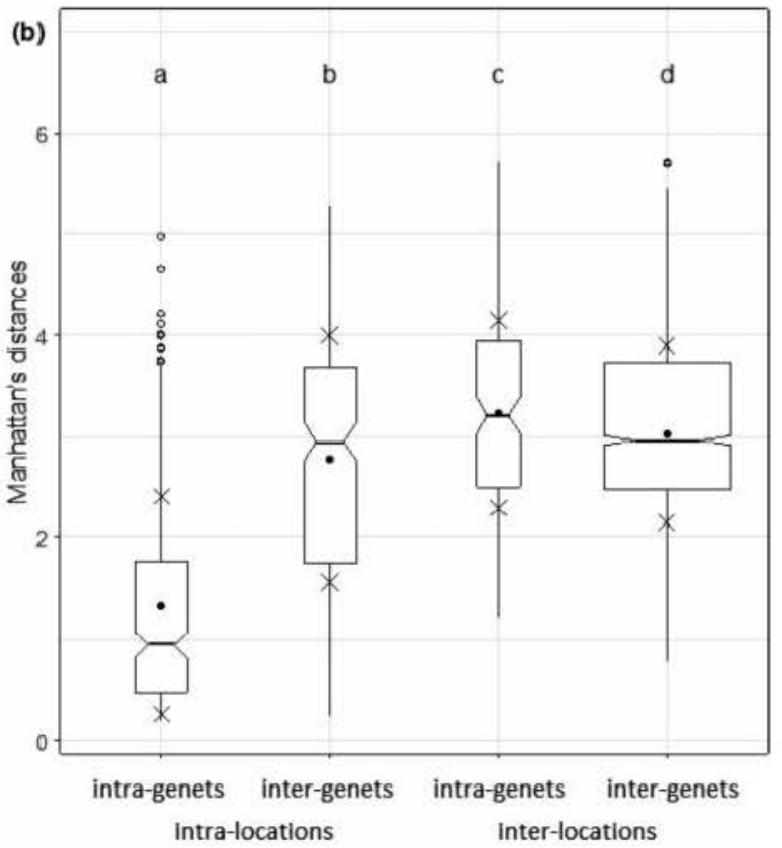

FIGURE 5 Intralocation differentiation and interlocation differentiation in symbiont microsatellite contents for the different host genetic structures (N148 data set). (a) Comparison of distance distributions within lineages (intra-) or between lineages (inter-) from the same sampling location (intralocations) or between different locations (interlocations). (b) Comparison of distance distributions within genet (intra-) or between genet (inter-) from the same sampling location (intralocations) or between different locations (interlocations). The global p-values for both comparisons ( $a$ and $b$ ) are $<2.2 \times 10^{-16}$ and tested with Kruskal-Wallis tests. The lowercase letters indicate the statistical differences. The boxes are the two first quartiles of distributions, and the whiskers are the third and the fourth quartiles. The black horizontal bars (in the boxes) are the medians (with IC95 figured with the notches). The dots correspond to the averages of Manhattan's distances of the distributions, and the standard deviation is given by the crosses. Blank points are outlier values 
FIGURE 6 Schematic illustration of the host and symbiont differentiation among sites according to our results. The colours of the sea anemones correspond to the host lineages or host lineages, and the symbols inside are the symbiont communities

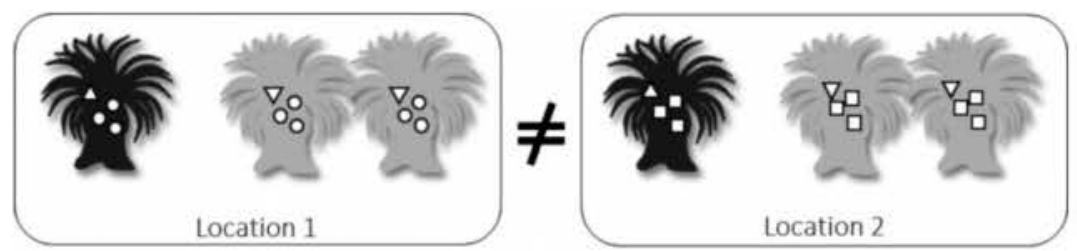

alluded to in Porro et al. (2019). To disperse, adult sea anemones may detach and move up to several metres away (Ayre, 1984; Mackie, 1974; Shick, 1991), but long-distance migration could likely occur by rafting attached to freely drifting natural (as wood) or artificial (as ships' bottoms) substrates (Jackson, 1986). The dispersal of asexual larvae as it occurs in some corals could also explain the distribution of clonal genets (Gélin et al., 2017), but it was not observed yet in A. viridis (Utrilla et al., 2019). In fine, even if established sea anemone clones have been considered as highly locally adapted (Ayre, 1985), migration and successful new establishment of ramets are not rare in $A$. viridis.

\subsection{Hosts from the same genetic lineage harbour different symbiont communities}

With both marker types (ITS2 and microsatellites), no correlation was revealed between the genetic distances among symbionts and the genetic distances among their hosts (Figures 3 and 4), suggesting that the closed vertical transmission is not the only mechanism of symbiont acquisition in adult hosts. Our results also showed that the symbiont ITS2 diversity was only, and strongly, linked to the geographical site of sampling. Microsatellite diversity was strongly linked to the sampling location as well (Table 3). The microsatellite markers also revealed a weak correlation of symbiont content with the host genetic lineage (Table 3), which would be expected considering that symbionts are transferred through the eggs in this species (Schäfer, 1984; Utrilla et al., 2019). This finding was summarized in Figure 6. It should also be noted that only one of the within-site comparisons of symbiont microsatellite size distribution between host lineages was significant, at Scandola, where a strong differentiation between the lineages of Med2 (K2) and Med4 (K4) occurred (Table S4). This was likely due to a large effect of host clonality on symbiont differentiation (preponderance of the genet R155 at this site; Figure $3 \mathrm{~b}$ and Table S5). The presence of this large genet is surprising and could reflect a sampling artefact but could also be the consequence of the dominance of a highly aggressive clone, a phenomenon already identified in sea anemones by Ayre and Grosberg (1995).

\subsection{Hosts from the same genet harbour different symbiont communities}

If symbionts are vertically transmitted, the individuals belonging to the same genet, present or not at the same site, should be dominated by the same symbiont community. We observed, however, that individuals from the same genet, but from different locations, were not more similar than individuals from different genets (Figure $5 b$, intragenet interlocation versus intergenet intra- or interlocation). Considering the high probability that the revealed microsatellite diversity is neutral, this result is strongly in favour of the occurrence of horizontal acquisition of symbionts at the adult stage in A. viridis, and thus against the hypothesis of an entirely closed vertical transmission of symbionts,

\subsection{A mixed-mode symbiont transmission in Anemonia viridis}

This result highlights the potential for a plastic response of $A$. viridis lineages to the environment by modifying their symbiont community composition. Previous studies stated that no genetic changes in the symbiont community composition occurred in A. viridis in response to environmental change between subtidal and intertidal habitats (Bythell et al., 1997) or different pH conditions (Borell et al., 2014; Suggett et al., 2012) or after living for a decade in proximity to cnidarians containing mostly clade $\mathrm{C}$ (genus Cladocopium now) symbionts (Hartle-Mougiou et al., 2012). These studies used ribosomal sequences as a genetic marker, but the flexibility has never been investigated at the symbiont diversity scale using marker analysis by NGS (ITS2 or microsatellite) or sampling geographically distant A. viridis populations. Such flexibility would be beneficial for an organism living in a diverse and changing environment such as this temperate sea anemone (see, e.g. Secord and Muller-Parker, 2005).

However, the mechanism involved in this symbiont flexibility cannot be unambiguously resolved yet as it could still be putatively due to (i) a renewal of symbiont content by horizontal acquisition from the environment at the adult stage or (ii) convergent changes in symbiont frequency within large and diverse inherited symbiont populations. In the coral Montipora capitata, comparing ITS2 sequence assemblages in eggs and their parent colonies, PadillaGamiño et al. (2012) demonstrated that the eggs harboured a large range of ITS2 sequences and that symbiont assemblages in the eggs were strongly influenced by symbiont composition of the parent colony, which in turn differed and reflected characteristics of their physical environment. In M. capitata, an environmental selection of the inherited symbiont diversity is then more plausible, as was also strongly suggested by Quigley et al. (2019) in another species of the same genus. However, these Montipora species harbour different genera (or species) of Symbiodiniaceae, known to have different ecophysiological profiles. Therefore, the relative proportions of these 
different symbiont strains within a host could very likely be influenced by local selection.

In our case, considering that $A$. viridis harbours only Temperate A Symbiodiniaceae, to explain the observed pattern of local similarity in symbiont composition among host genets and even lineages by convergent selection without horizontal acquisition, one would have to imagine that each host larva, independently of its mother's affiliation to a clone or to a reproductively isolated lineage, should inherit the whole complement of symbiont genetic diversity that would allow such local differentiation. This would mean that adult sea anemones belonging to genetically differentiated lineages still manage to transfer a wide array of microsatellite diversity to their offspring, despite generations of local adaptation and successive bottlenecks (at the production of the ovule). A mixed-mode of symbiont acquisition with episodes of horizontal acquisition from local environment is the most parsimonious explanation of the distribution of symbiotic diversity we observed. Indeed, a very similar pattern of variability in symbiont population among host ramets had also been observed in Acropora palmata, a coral species that only acquires its symbiont from the environment at each generation (Baums et al., 2014).

Additional horizontal symbiont acquisition in hosts with maternal vertical symbiont transmission has already been suggested in some corals such as Pocillopora meandrina, Pocillopora damicornis, Stylophora pistillata and Seriatopora hystrix (Boulotte et al., 2016; Byler et al., 2013; Magalon et al., 2006; Quigley et al., 2018). In addition, analysing specifically within-colony symbiont diversity in Pocillopora sp., Pettay et al. (2011), also strongly suggested that switching may occur between clonal host lineages and that this species can mix vertical and horizontal symbiont acquisition. Mixedmode symbiont acquisition is frequent in symbiotic cnidarians and supports the conclusions of Ebert (2013) that symbionts with mixedmode transmission may be the most common type of symbionts in animals.

\section{ACKNOWLEDGEMENTS}

This work was supported by the ANR Bioadapt research program 'AdaCni' (ANR-12-ADAP-0016) as a PhD grant to C.M. and by a doctoral fellowship from the French Ministère de l'Enseignement Supérieur et de la Recherche to B.P. We thank A.Pey and A. Haguenauer for their contribution to the sampling effort. We thank M.Suez and D.Higuet for constructive discussion about MicNeSs algorithm and D.B. for her kind and wise 'after-sales service' for RClone. We thank R.Christen for his scientific discussions and the access to the computing facilities. We also thank P-A.Gagnaire and L.Sromek for the RAD-Seq individual tags; P.Barbry from IPMC who provided access to the CovarisB sonicator and V.Magnone and M-J. Arguel for their help during its utilization. We also thank C.Fauvelot for her attentive reading and her suggestions. The authors thank the anonymous reviewers for their constructive comments.

\section{CONFLICT OF INTEREST}

The authors declare that they have no conflict of interest.

\section{AUTHOR CONTRIBUTIONS}

B.P. and C.M. prepared the samples from field sample to DNA extraction, B.P. and T.Z. developed and set up molecular marker design, C.M. prepared the RAD-Seq libraries, B.P. and B.C.C.H. did postsequencing in silico treatments and analyses. B.P., P.F. and D.F. designed the research and participated to the writing. Finally, B.C.C.H., C.R.V., E.R. and C.M. reviewed the paper.

\section{ORCID}

Barbara Porro (10) https://orcid.org/0000-0003-0294-1886 Thamilla Zamoum (D) https://orcid.org/0000-0002-2649-5772 Cédric Mallien (Dttps://orcid.org/0000-0001-8701-6520 Benjamin C. C. Hume (D) https://orcid.org/0000-0001-7753-3903 Christian R. Voolstra (D) https://orcid.org/0000-0003-4555-3795 Eric Röttinger (D) https://orcid.org/0000-0002-2938-6774 Paola Furla (1) https://orcid.org/0000-0001-9899-942X Didier Forcioli https://orcid.org/0000-0002-5505-0932

\section{REFERENCES}

Abdoullaye, D., Acevedo, I., Adebayo, A. A., Behrmann-Godel, J., Benjamin, R. C., Bock, D. G., Born, C., Brouat, C., Caccone, A., Cao, L. Z., Casado-Amezúa, P., Catanéo, J., Correa-Ramirez, M. M., Cristescu, M. E., Dobigny, G., Egbosimba, E. E., Etchberger, L. K., Fan, B., \& Fields, P. D. ... Zhou, Y. (2010). Permanent genetic resources added to molecular ecology resources database 1 August 2009-30 September 2009. Molecular Ecology Resources, 10(1), 232-236. https://doi.org/10.1111/j.1755-0998.2009.02796.x

Ayre, D. J. (1984). Effects of environment and population density on the sea anemone Actinia tenebrosa. Marine and Freshwater Research. 35(6), 735-746. https://doi.org/10.1071/mf9840735

Ayre, D. J. (1985). Localized adaptation of clones of the sea anemone Actinia Tenebrosa. Evolution, 39(6), 1250-1260. https://doi. org/10.1111/j.1558-5646.1985.tb05691.x

Ayre, D. J., \& Grosberg, R. K. (1995). Aggression, habituation, and clonal coexistence in the sea anemone Anthopleura elegantissima. The American Naturalist, 146(3), 427-453. https://doi.org/10.1086/285808

Bailleul, D., Stoeckel, S., \& Arnaud-Haond, S. (2016). RClone: A package to identify MultiLocus Clonal Lineages and handle clonal data sets in R. Methods in Ecology and Evolution, 7(8), 966-970. https://doi. org/10.1111/2041-210X.12550

Baird, A. H., Guest, J. R., \& Willis, B. L. (2009). Systematic and biogeographical patterns in the reproductive biology of Scleractinian corals. Annual Review of Ecology, Evolution, and Systematics, 40(1), 551-571. https://doi.org/10.1146/annurev.ecolsys.110308.120220

Baumann, P. (2005). Biology of bacteriocyte-associated endosymbionts of plant sap-sucking insects. Annual Review of Microbiology, 59(1), 155-189. https://doi.org/10.1146/annur ev.micro.59.030804.121041

Baums, I. B., Devlin-Durante, M. K., \& LaJeunesse, T. C. (2014). New insights into the dynamics between reef corals and their associated dinoflagellate endosymbionts from population genetic studies. Molecular Ecology, 23(17), 4203-4215. https://doi.org/10.1111/ mec.12788

Borell, E. M., Steinke, M., Horwitz, R., \& Fine, M. (2014). Increasing $\mathrm{pCO} 2$ correlates with low concentrations of intracellular 
dimethylsulfoniopropionate in the sea anemone Anemonia viridis. Ecology and Evolution, 4(4), 441-449. https://doi.org/10.1002/ ece3.946

Bouckaert, R., Heled, J., Kühnert, D., Vaughan, T., Wu, C.-H., Xie, D. Suchard, M. A., Rambaut, A., \& Drummond, A. J. (2014). BEAST 2: a software platform for Bayesian evolutionary analysis. PLOS Computational Biology, 10(4), e1003537. https://doi.org/10.1371/ journal.pcbi.1003537

Boulotte, N. M., Dalton, S. J., Carroll, A. G., Harrison, P. L., Putnam, H. M., Peplow, L. M., \& van Oppen, M. J. (2016). Exploring the Symbiodinium rare biosphere provides evidence for symbiont switching in reef-building corals. The ISME Journal, 10(11), 2693-2701. https:// doi.org/10.1038/ismej.2016.54

Boyer, F., Mercier, C., Bonin, A., Le Bras, Y., Taberlet, P., \& Coissac, E. (2016). OBITOOLs: A UNIX -inspired software package for DNA metabarcoding. Molecular Ecology Resources, 16(1), 176-182. https://doi. org/10.1111/1755-0998.12428

Brading, P., Warner, M. E., Davey, P., Smith, D. J., Achterberg, E. P., \& Suggett, D. J. (2011). Differential effects of ocean acidification on growth and photosynthesis among phylotypes of Symbiodinium (Dinophyceae). Limnology and Oceanography, 56(3), 927-938. https:// doi.org/10.4319/lo.2011.56.3.0927

Bryant, D., Bouckaert, R., Felsenstein, J., Rosenberg, N. A., \& RoyChoudhury, A. (2012). Inferring species trees directly from biallelic genetic markers: bypassing gene trees in a full coalescent analysis. Molecular Biology and Evolution, 29(8), 1917-1932. https://doi. org/10.1093/molbev/mss086

Byler, K. A., Carmi-Veal, M., Fine, M., \& Goulet, T. L. (2013). Multiple symbiont acquisition strategies as an adaptive mechanism in the coral Stylophora pistillata. PLoS One, 8(3), e59596. https://doi.org/10.1371/ journal.pone.0059596

Bythell, J. C., Douglas, A. E., Sharp, V. A., Searle, J. B., \& Brown, B. E. (1997). Algal genotype and photoacclimatory responses of the symbiotic alga Symbiodinium in natural populations of the sea anemone Anemonia viridis. Proceedings of the Royal Society of London. Series B: Biological Sciences, 264(1386), 1277-1282. https://doi.org/10.1098/ rspb.1997.0176

Casado-Amezúa, P., Machordom, A., Bernardo, J., \& GonzálezWangüemert, M. (2014). New insights into the genetic diversity of zooxanthellae in Mediterranean anthozoans. Symbiosis, 63(1), 41-46. https://doi.org/10.1007/s13199-014-0286-y

Catanéo, J., Ortu, M.-F., Furla, P., \& Forcioli, D. (2009). Development of microsatellite loci from a Mediterranean symbiotic gorgonian, Eunicella singularis (Cnidaria, Anthozoa), and its temperate-A Symbiodinium. Molecular Ecology Resources, 10, 232-236. https://dol. org/10.1111/j.1755-0998.2009.02796.x

Chifman, J., \& Kubatko, L. (2014). Quartet inference from SNP data under the coalescent model. Bioinformatics, 30(23), 3317-3324. https://doi. org/10.1093/bioinformatics/btu530

Clavijo, J. M., Donath, A., Serôdio, J., \& Christa, G. (2018). Polymorphic adaptations in metazoans to establish and maintain photosymbioses. Biological Reviews, 93(4), 2006-2020. https://doi.org/10.1111/ brv. 12430

Coffroth, M. A., \& Santos, S. R. (2005). Genetic diversity of symbiotic dinoflagellates in the genus Symbiodinium. Protist, 156(1), 19-34. https://doi.org/10.1016/j.protis.2005.02.004

Cornuet, J.-M., Ravigué, V., \& Estoup, A. (2010). Inference on population history and model checking using DNA sequence and microsatellite data with the software DIYABC (v.1.0). BMC Bioinformatics, 11. https://doi.org/10.1186/1471-2105-11-401

Danecek, P., Auton, A., Abecasis, G., Albers, C. A., Banks, E., DePristo, M. A., Handsaker, R. E., Lunter, G., Marth, G. T., Sherry, S. T., McVean, G., \& Durbin, R. (2011). The variant call format and VCFtools. Bioinformatics, 27(15), 2156-2158. https://doi.org/10.1093/bioin formatics/btr330
Davy, S. K., Allemand, D., \& Weis, V. M. (2012). Cell biology of cnidarian-dinoflagellate symbiosis. Microbiology and Molecular Biology Reviews, 76(2), 229-261. https://doi.org/10.1128/MMBR.05014-11

Davy, S. K., Lucas, I. A. N., \& Turner, J. R. (1996). Carbon budgets in temperate anthozoan-dinoflagellate symbioses. Marine Biology, 126(4), 773-783. https://doi.org/10.1007/BF00351344

Eaton, D. A. R. (2014). PyRAD: Assembly of de novo RADseq loci for phylogenetic analyses. Bioinformatics, 30(13), 1844-1849. https:// doi.org/10.1093/bioinformatics/btu121

Ebert, D. (2013). The epidemiology and evolution of symbionts with mixed-mode transmission. Annual Review of Ecology, Evolution, and Systematics, 44(1), 623-643. https://doi.org/10.1146/annurev-ecols ys-032513-100555

Forskål, P. (1775). Descriptiones animalium, avium, amphibiorum, piscium, insectorum, vermium; quae in itinere orientali observait. : Mölleri, Havniae.

Frichot, E., \& François, O. (2015). LEA: An R package for landscape and ecological association studies. Methods in Ecology and Evolution, 6(8), 925-929. https://doi.org/10.1111/2041-210X.12382

Gélin, P., Fauvelot, C., Mehn, V., Bureau, S., Rouzé, H., \& Magalon, H. (2017). Superclone expansion, long-distance clonal dispersal and local genetic structuring in the coral Pocillopora damicornis type $\beta$ in reunion Island, South Western Indian Ocean. PLOS ONE, 12(1), e0169692. https://doi.org/10.1371/journal.pone.0169692

Goudet, J., \& Jombart, T. (2015). Hierfstat: Estimation and tests of hierarchical F-statistics. R Package Version 0.04-22.

Harper, J. L. (1977). Population biology of plants. : Academic Press. CABDirect2.

Hartle-Mougiou, K., D'Angelo, C., Smith, E. G., Burt, J., West, P., \& Wiedenmann, J. (2012). Diversity of zooxanthellae from corals and sea anemones after long-term aquarium culture. Journal of the Marine Biological Association of the United Kingdom, 92(4), 687-691. https:// doi.org/10.1017/S0025315411001159

Henry, L. M., Peccoud, J., Simon, J.-C., Hadfield, J. D., Maiden, M. J. C., Ferrari, J., \& Godfray, H. C. J. (2013). Horizontally transmitted symbionts and host colonization of ecological niches. Current Biology, 23(17), 1713-1717. https://doi.org/10.1016/j.cub.2013.07.029

Hipp, A. L. (2014). RADami: R package for phylogenetic analysis of RADseq data. R Package Version, 1-0.

Hoffmann, R. J. (1986). Variation in contribution of asexual reproduction to the genetic structure of populations of the sea anemone Metridium senile. Evolution, 40(2), 357-365. https://doi. org/10.1111/j.1558-5646.1986.tb00477.x

Howells, E. J., Bauman, A. G., Vaughan, G. O., Hume, B. C. C., Voolstra, C. R., \& Burt, J. A. (2020). Corals in the hottest reefs in the world exhibit symbiont fidelity not flexibility. Molecular Ecology, 29(5), 899-911. https://doi.org/10.1111/mec.15372

Howells, E. J., Beltran, V. H., Larsen, N. W., Bay, L. K., Willis, B. L., \& van Oppen, M. J. H. (2012). Coral thermal tolerance shaped by local adaptation of photosymbionts. Nature Climate Change, 2(2), 116-120. https://doi.org/10.1038/nclimate1330

Hume, B. C. C. (2019). didillysquat/SymPortal_framework: V0.2.7. Zenodo. 10.5281 /zenodo. 2620837

Hume, B. C. C., Smith, E. G., Ziegler, M., Warrington, H. J. M., Burt, J. A., LaJeunesse, T. C., \& Voolstra, C. R. (2019). SymPortal: A novel analytical framework and platform for coral algal symbiont next-generation sequencing ITS2 profiling. Molecular Ecology Resources, 19(4), 1063-1080. https://doi.org/10.1111/1755-0998.13004

Jackson, J. B. C. (1986). Modes of dispersal of clonal benthic invertebrates: Consequences for species' distributions and genetic structure of local populations. Bulletin of Marine Science, 39, 19.

Kamvar, Z. N., Tabima, J. F., \& Grünwald, N. J. (2014). Poppr: An R package for genetic analysis of populations with clonal, partially clonal, and/or sexual reproduction. PeerJ, 2, e281. https://doi.org/10.7717/ peerj.281 
Kaufman, M. R., Ikeda, Y., Patton, C., van Dykhuizen, G., \& Epel, D. (1998). Bacterial symbionts colonize the accessory Nidamental gland of the squid Loligo opalescens via horizontal transmission. The Biological Bulletin, 194(1), 36-43. https://doi.org/10.2307/1542511

LaJeunesse, T. C., Parkinson, J. E., Gabrielson, P. W., Jeong. H. J., Reimer, J. D., Voolstra, C. R., \& Santos, S. R. (2018). Systematic revision of symbiodiniaceae highlights the antiquity and diversity of coral endosymbionts. Current Biology, 28(16), 2570-2580.e6. https://doi. org/10.1016/j.cub.2018.07.008

Leaché, A. D., Fujita, M. K., Minin, V. N., \& Bouckaert, R. R. (2014). Species delimitation using genome-wide SNP data. Systematic Biology, 63(4), 534-542. https://doi.org/10.1093/sysbio/syu018

Mackie, G. O. (1974). Locomotion, Flotation, and Dispersal. Leonard Muscatine Coelenterate Biology: Reviews and New Perspectives, (pp. 313-357). New York: Academic Press.

Magalon, H., Baudry, E., Husté, A., Adjeroud, M., \& Veuille, M. (2006). High genetic diversity of the symbiotic dinoflagellates in the coral Pocillopora meandrina from the South Pacific. Marine Biology, 148(5), 913-922. https://doi.org/10.1007/s00227-005-0133-z

Mallien, C., Porro, B., Zamoum, T., Olivier, C., Wiedenmann, J., Furla, P., \& Forcioli, D. (2017). Conspicuous morphological differentiation without speciation in Anemonia viridis (Cnidaria, Actiniaria). Systematics and Biodiversity, 16(3), 271-286. https://doi.org/10.1080/14772 000.2017 .1383948

Margulis, L., \& R. Fester (Eds.) (1991). Symbiosis as a source of evolutionary innovation: Speciation and morphogenesis. MIT Press.

Miller, S. A., Dykes, D. D., \& Polesky, H. F. (1988). A simple salting out procedure for extracting DNA from human nucleated cells. Nucleic Acids Research, 16(3), 1215. https://doi.org/10.1093/nar/16.3.1215

Moran, N. A., \& Wernegreen, J. J. (2000). Lifestyle evolution in symbiotic bacteria: Insights from genomics. Trends in Ecology \& Evolution, 15(8), 321-326. https://doi.org/10.1016/S0169-5347(00)01902-9

Muller-Parker, G., \& Davy, S. K. (2005). Temperate and tropical algal-sea anemone symbioses. Invertebrate Biology, 104-123.

Neave, M. J., Rachmawati, R., Xun, L., Michell, C. T., Bourne, D. G., Apprill, A., \& Voolstra, C. R. (2017). Differential specificity between closely related corals and abundant Endozoicomonas endosymbionts across global scales. The ISME Journal, 11(1), 186-200. https://doi. org/10.1038/ismej.2016.95

Nelsen, M. P., \& Gargas, A. (2008). Dissociation and horizontal transmission of codispersing lichen symbionts in the genus Lepraria (Lecanorales: Stereocaulaceae). New Phytologist, 177(1), 264-275. https://doi.org/10.1111/j.1469-8137.2007.02241.x

Oksanen, J., Blanchet, F. G., Friendly, M., Kindt, R., Legendre, P., McGlinn, D., Simpson, G. L., Solymos, P., Stevens, M. H. H., \& Wagner, H. (2016). vegan: Community Ecology Package. (Version $\mathrm{R}$ package version 2.4-0.). Retrieved from https://CRAN.R-proje ct.org $/$ package $=$ vegan

Padilla-Gamiño, J. L., Pochon, X., Bird, C., Concepcion, G. T., \& Gates, R. D. (2012). From parent to gamete: vertical transmission of Symbiodinium (Dinophyceae) ITS2 sequence assemblages in the reef building coral Montipora capitata. PLoS One, 7(6), e38440. https://doi.org/10.1371/ journal.pone.0038440

Paradis, E., Claude, J., \& Strimmer, K. (2004). APE: analyses of phylogenetics and evolution in R language. Bioinformatics, 20(2), 289-290. https://doi.org/10.1093/bioinformatics/btg412

Parkinson, J. E., \& Baums, I. B. (2014). The extended phenotypes of marine symbioses: Ecological and evolutionary consequences of intraspecific genetic diversity in coral-algal associations. Frontiers in Microbiology, 5, https://doi.org/10.3389/fmicb.2014.00445

Pembleton, L. W., Cogan, N. O. I., \& Forster, J. W. (2013). StAMPP: An $R$ package for calculation of genetic differentiation and structure of mixed-ploidy level populations. Molecular Ecology Resources, 13(5), 946-952. https://doi.org/10.1111/1755-0998.12129
Pettay, D. T., Wham, D. C., Pinzón, J. H., \& Lajeunesse, T. C. (2011). Genotypicdiversityand spatial-temporal distribution of Symbiodinium clones in an abundant reef coral. Molecular Ecology, 20(24), 51975212. https://doi.org/10.1111/j.1365-294X.2011.05357.x

Porro, B., Mallien, C., Hume, B. C. C., Pey, A., Aubin, E., Christen, R., Voolstra, C. R., Furla, P., \& Forcioli, D. (2019). The many faced symbiotic snakelocks anemone (Anemonia viridis, Anthozoa): Host and symbiont genetic differentiation among colour morphs. Heredity, 124(2), 351-366. https://doi.org/10.1038/s41437-019-0266-3

Quigley, K. M., Strader, M. E., \& Matz, M. V. (2018). Relationship between Acropora millepora juvenile fluorescence and composition of newly established Symbiodinium assemblage. PeerJ, 6, e5022. https://doi. org/10.7717/peerj.5022

Quigley, K. M., Willis, B. L., \& Kenkel, C. D. (2019). Transgenerational inheritance of shuffled symbiont communities in the coral Montipora digitata. Scientific Reports, 9(1), 1-11. https://doi.org/10.1038/s4159 8-019-50045-y

R Core Team (2018). R: A Language and Environment for Statistical Computing (Version 3.5.1). R Foundation for Statistical Computing. Retrieved from http://www.R-project.org/

Reynolds, J. M., Bruns, B. U., Fitt, W. K., \& Schmidt, G. W. (2008). Enhanced photoprotection pathways in symbiotic dinoflagellates of shallow-water corals and other cnidarians. Proceedings of the National Academy of Sciences, 105(36), 13674-13678. https://doi. org/10.1073/pnas.0805187105

Richier, S., Furla, P., Plantivaux, A., Merle, P.-L., \& Allemand, D. (2005). Symbiosis-induced adaptation to oxidative stress. Journal of Experimental Biology, 208(2), 277-285. https://doi.org/10.1242/ jeb. 01368

Roberty, S., Furla, P., \& Plumier, J.-C. (2016). Differential antioxidant response between two Symbiodinium species from contrasting environments. Plant, Cell \& Environment, 39(12), 2713-2724. https://doi. org/10.1111/pce.12825

Rohwer, F., Seguritan, V., Azam, F., \& Knowlton, N. (2002). Diversity and distribution of coral-associated bacteria. Marine Ecology Progress Series, 243, 1-10. https://doi.org/10.3354/meps243001

Rowan, R., \& Knowlton, N. (1995). Intraspecific diversity and ecological zonation in coral-algal symbiosis. Proceedings of the National Academy of Sciences, 92(7), 2850-2853. https://doi.org/10.1073/ pnas.92.7.2850

Sabourault, C., Ganot, P., Deleury, E., Allemand, D., \& Furla, P. (2009). Comprehensive EST analysis of the symbiotic sea anemone, Anemonia viridis. BMC Genomics, 10(1), 333. https://doi. org/10.1186/1471-2164-10-333

Sauer, K. P. (1986). Strategien zeitlicher und räumlicher Einnischung. Verhandlungen Der Deutschen Zoologischen Gesellschaft, 79, 11-30.

Sauer, K. P., Müller, M., \& Weber, M. (1986). Alloimmune memory for glycoproteid recognition molecules in sea anemones competing for space. Marine Biology, 92(1), 73-79. https://doi.org/10.1007/BF003 92748

Savage, A. M., Goodson, M. S., Visram, S., Trapido-Rosenthal, H., Wiedenmann, J., \& Douglas, A. E. (2002). Molecular diversity of symbiotic algae at the latitudinal margins of their distribution: Dinoflagellates of the genus Symbiodinium in corals and sea anemones. Marine Ecology Progress Series, 244. 17-26. https://doi. org/10.3354/meps 244017

Schäfer, W. (1984). Fortpflanzung und Entwicklung von Anemonia sulcata (Anthozoa, Actiniaria). I: Fortpflanzungszyklus und Struktur der Oocyten vor und nach der Besamung. Helgoländer Meeresuntersuchungen, 38(2), 135-148.

Secord, D., \& Muller-Parker, G. (2005). Symbiont distribution along a light gradient within an intertidal cave. Limnology and Oceanography, 50(1), 272-278. https://doi.org/10.4319/lo.2005.50.1.0272

Shick, J. M. (1991). A Functional Biology of Sea Anemones. Springer. 
Silverstein, R. N., Cunning, R., \& Baker, A. C. (2015). Change in alga symbiont communities after bleaching, not prior heat exposure, increases heat tolerance of reef corals. Global Change Biology, 21(1), 236-249. https://doi.org/10.1111/gcb.12706

Stat, M., Pochon, X., Cowie, R., \& Gates, R. (2009). Specificity in communities of Symbiodinium in corals from Johnston Atoll. Marine Ecology Progress Series, 386, 83-96. https://doi.org/10.3354/meps08080

Stewart, F. J., Young, C. R., \& Cavanaugh, C. M. (2008). Lateral symbiont acquisition in a maternally transmitted chemosynthetic clam endosymbiosis. Molecular Biology and Evolution, 25(4), 673-687. https:// doi.org/10.1093/molbev $/ \mathrm{msn010}$

Suez, M., Behdenna, A., Brouillet, S., Graça, P., Higuet, D., \& Achaz, G. (2016). MicNeSs: Genotyping microsatellite loci from a collection of (NGS) reads. Molecular Ecology Resources, 16(2), 524-533. https://doi. org/10.1111/1755-0998.12467

Suggett, D. J., Hall-Spencer, J. M., Rodolfo-Metalpa, R., Boatman, T. G., Payton, R., Tye Pettay, D., \& Lawson, T. (2012). Sea anemones may thrive in a high CO2 world. Global Change Biology, 18(10), 3015-3025. https://doi.org/10.1111/j.1365-2486.2012.02767.x

Suggett, D. J., Warner, M. E., \& Leggat, W. (2017). Symbiotic dinoflagellate functional diversity mediates coral survival under ecological crisis. Trends in Ecology \& Evolution, 32(10), 735-745. https://doi. org/10.1016/j.tree.2017.07.013

Suggett, D. J., Warner, M. E., Smith, D. J., Davey, P., Hennige, S., \& Baker, N. R. (2008). Photosynthesis and production of hydrogen peroxide by Symbiodinium (Pyrrhophyta) Phylotypes with different thermal Tolerances1. Journal of Psychology, 44(4), 948-956. https://doi. org/10.1111/j.1529-8817.2008.00537.x

Swofford, D. L. (1998). Phylogenetic analysis using parsimony (paup) (Version 4). Sinauer Associates.

Swofford, D. L. (2001). PAUP*; Phylogenetic Analysis Using Parsimony (and other methods) 4.0.b5.

Tchernov, D., Gorbunov, M. Y., de Vargas, C., Yadav, S. N., Milligan, A. J., Häggblom, M., \& Falkowski, P. G. (2004). Membrane lipids of symbiotic algae are diagnostic of sensitivity to thermal bleaching in corals. Proceedings of the National Academy of Sciences of the United States of America, 101(37), 13531-13535. https://doi.org/10.1073/ pnas.0402907101

Theis, K. R., Dheilly, N. M., Klassen, J. L., Brucker, R. M., Baines, J. F., Bosch, T. C. G., Cryan, J. F., Gilbert, S. F., Goodnight, C. J., Lloyd, E. A., Sapp, J., Vandenkoornhuyse, P., Zilber-Rosenberg, I., Rosenberg, E., \& Bordenstein, S. R. (2016). Getting the hologenome concept right: an eco-evolutionary framework for hosts and their microbiomes. Msystems, 1(2), e00028-e116. https://doi.org/10.1128/mSyst ems.00028-16
Utrilla, O., Castro-Claros, J. D., Urra, J., Navas, F. D., \& Salas, C. (2019). Reproduction of the anthozoan Anemonia sulcata (Pennant, 1777) in southern Spain: From asexual reproduction to putative maternal care. Marine Biology, 166(8), 111. https://doi.org/10.1007/s0022 7-019-3558-5

Ventura, P., Jarrold, M. D., Merle, P. L., Barnay-Verdier, S., Zamoum, T., Rodolfo-Metalpa, R., Calosi, P., \& Furla, P. (2016). Resilience to ocean acidification: Decreased carbonic anhydrase activity in sea anemones under high pCO2 conditions. Marine Ecology Progress Series, 559. 257-263. https://doi.org/10.3354/meps11916

Visram, S., Wiedenmann, J., \& Douglas, A. E. (2006). Molecular diversity of symbiotic algae of the genus Symbiodinium (Zooxanthellae) in cnidarians of the Mediterranean Sea. Journal of the Marine Biological Association of the UK, 86(06), 1281. https://doi.org/10.1017/S0025 315406014299

Wiedenmann, J., Kraus, P., Funke, W., \& Vogel, W. (2000). The relationship between different morphs of Anemonia aff. Sulcata evaluated by DNA fingerprinting (Anthozoa, Actinaria). Ophelia, 52(1), 57-64. https://doi.org/10.1080/00785236.1999.10409419

Wiedenmann, J., Röcker, C., \& Funke, W. (1999). The morphs of Anemonia aff. Sulcata (Cnidaria, Anthozoa) in particular consideration of the ectodermal pigments. In J. Pfadenhauer (Ed.), Verhandlungen der Gesellschaft für Ökologie, Vol. 29 (pp. 497-503). Spektrum Akademischer Verlag.

Zheng, X. (2012). SNPRelate: Parallel computing toolset for genome-wide association studies (Version $\mathrm{R}$ package version 1.11.1).

Zilber-Rosenberg, I., \& Rosenberg, E. (2008). Role of microorganisms in the evolution of animals and plants: The hologenome theory of evolution. FEMS Microbiology Reviews, 32(5), 723-735. https://doi. org/10.1111/j.1574-6976.2008.00123.x 